\section{Research Article}

(c) 2022 Sharma et al. This is an open access article licensed under the Creative Commons Attribution-NonCommercial 4.o International License (https://creativecommons.org/licenses/by-nc/4.o/)

\title{
Adoption of Blockchain Technology Based Accounting Platform
}

\author{
Asha Sharma' \\ Shurveer S. Bhanawat ${ }^{2}$ \\ Raj Bahadur Sharma ${ }^{3}$ \\ ${ }^{1}$ Assistant Professor, \\ Department of Accountancy and Business Statistics, \\ Mohanlal Sukhadia University, University Rd, Ganapati Nagar, \\ Udaipur, Rajasthan 313001, India \\ ${ }^{2}$ Professor \& Head, \\ Department of Accountancy and Business Statistics, \\ Mohanlal Sukhadia University, University Rd, Ganapati Nagar, \\ Udaipur, Rajasthan 313001, India \\ ${ }^{3}$ Assistant Professor, \\ Department of Accounting, College of Business Administration, \\ University of Bahrain, Bahrain International Circuit, \\ Zallaq, Bahrain
}

DOI: https://doi.org/10.36941/ajis-2022-0042

\section{Abstract}

Accounting has always been influenced by digital technology, although most of it has been replacing analogue instruments with digital versions. A blockchain is a digital ledger that is used to record transactions between different participants in a network. It is an internet-based, peer-to-peer distributed ledger that contains all transactions since its inception. Blockchain technology has the potential to revolutionize the world humanity implementing in the business based on the concept of transmitting valuable digital assets like bitcoin without the need of a third-party intermediary. Blockchain is considered as a type of database or a sort of digital ledger, which is widely used by many financial organizations. It's a distributed ledger which keeps records of immutable and verifiable data. This blockchain technology permits decentralized ledger transactions to be produced without the intervention of a third party. Because of its decentralization, networks have a high degree of protection. The aim of the study is to investigate various decisions making factors, affecting in adopting blockchain technology in the field of accounting. The result showed that secure and private, transparent and auditable, immutable, better transparency, reduce cost, transparency, real-time transaction, and flexible are most likely influencing factors in adoption of blockchain technology. The result indicates that the Quorum, Sap Hana, and Ethereum, platforms are most consistent and trusted platforms for block chain technology and the blockchain platforms are found most suitable, secured and stronger platform.

Keywords: Blockchain Technology, Scalability, Ethereum 


\section{Introduction}

Every business organization is required to record transactions in their books of accounts which maintain integrity of that business organization. Accountancy is one of the oldest professions in the world. Throughout its thousands of years of existence, historical accounting never progressed anything more than a single-entry accounting system. For each transaction, a one-sided accounting entry is used in the single-entry accounting system. This system has major limitations due to the single record and lack of crosschecking, as errors cannot be detected and tracked, allowing for plenty of possibilities for fraud. However, Blockchains technology is relatively closing supply of an immutable record of transactions, allow for the sharing of transaction data that is dynamically synced across multiple locations. Such kind of information sharing eliminates transaction-level reconciliations and makes it easier to develop continuous audits. For auditors, this opens up the possibility of moving from a periodic to a continuous process that could include the related parties to a transaction at the same time with the help of intermediaries. In order to establish trust and maintain integrity, users go through powerful intermediaries like banks, governments, and big technology companies. These intermediaries confirm our identities and enable us to transfer assets; they clear and settle the transactions and keep records. Over time, the users have been depending on large companies like Intel, Microsoft, Alphabet, Amazon, Facebook, Alibaba, etc. Right now, these are real rulers of the world. In many ways, users are depending on these companies globally for online transactions and value transfer. "Trust" is the cornerstone for all interactions user have among different entities, human or otherwise. User interact freely with those user trust. User listen to those user trust with an open mind. But the limitation of these intermediaries is their vulnerability to hackers. Most organizations today operate with a centralized command and control approach. All data are stored on a single point. It gives space for cyber attackers. Blockchain solves this problem. Now, trust can be achieved by cryptography, collaboration, and clever code, not by intermediaries. Blockchain technology-based accounting systems can be adopted by the entities. Accessibility, anonymity, immutability, no intermediary, and real-time transactions are some of the key features of blockchain (Dutta, 2020). Blockchain is a decentralized system that shared the power of distribution of information equally to its all stakeholders. Being a transparent technique, all the transactions on the blockchain can be viewed by any person. In the blockchain, every data is available to every stakeholder, and it can be controlled everything contains a block. Internet services are like a democratic system of thumb rule of governing by the people, for the people, and to the people. As there is no central authority to control the system, the customers of blockchain seem the king.

\section{Blockchain Technology based Accounting Platforms}

Blockchain platforms allow people a company or a developer to build blockchain frameworks to develop and host applications on the blockchain. They can be of various types like permissioned or permissionless. There are many platforms available like Bitcoin, Ethereum, Hyperledger, R3, Ripple, Obyte, SapHana, and EOS. Followings are the information of the blockchain platform:

\section{$2.1 \quad$ Ethereum}

Ethereum is a platform for recording the transaction and distributed public ledger. Ethereum is a platform for providing decentralized records to stakeholders by combining various features. This platform is also providing services like bitcoin's and enables us to run a smart contract on it. Complex applications such as financial exchanges and insurance contracts can be applied with help of smart contract applications on Ethereum's platform. Ethereum fulfils the need of recording transactions as well as proof of verification and validation for its network users. 


\subsection{SAP HANA Blockchain Service}

SAP Cloud Platform is providing services in disrupting technology of the recent time in today's world i. e. blockchain technology. This Blockchain platform allows users to construct blockchain-based apps in the cloud. SAP HANA Blockchain Service offers users the ability to link blockchain data with SAP HANA master/transaction data to provide a comprehensive analytical solution.

\subsection{Obyte: A ledger without middlemen}

Obyte is a platform to record data and documents. It is also based on the concept of a distributed ledger. Unlike centralized ledgers, Obyte ledger is based on the technology to provide decentralized, disintermediated, free, equal, and open service platforms.

\subsection{Quorum}

JP Morgan group has brought this platform of the latest development in form of blockchain. Quorum is a distributed ledger technology that is mostly applied in the financial sector. The main objective of the platform is to provide a permission implementation of Ethereum. Its unique feature is to provide supports transactions and contract privacy. The functioning of Quorum is similar to Ethereum but it is different on the basis of better performance, Voting-based consensus mechanisms, networking facility, and security and privacy of contract and transaction

\subsection{Hyperledger}

Hyperledger is an open-source platform developing stable frameworks. Hyperledger Fabrics are based on various components, such as consensus and membership services. A broad range of industry use cases is satisfied with its unique, and versatile design. It offers a modular approach to a consensus that permits performance at scale while preserving privacy.

\section{Review of Literature}

Aslam, J. et al (2021) study based on the oil industry' explored that attraction towards Blockchain technology is largely enhancing these days. The majority of supply-chain-related industries intend to use Blockchain technology. The unique features for obtaining more popularity and demand are realtime information exchange, cyber-security, transparency, reliability, traceability, and visibility. Farshidi, S., Jansen, S., España, S., \&Verkleij, J. (2020), study related to the 'Decision support for blockchain platform selection: Three industry case studies' studied about 28 blockchain platforms here. The selection of a blockchain platform was modelled as an MCDM problem, which includes assessing a set of alternatives while taking into consideration a set of decision criteria. Orji I.J. et al (2020) explore that the fright logistic industry affected by the different factors of influence blockchain when adoption of blockchain technologies. There are three topmost ranked significant factors 'availability of specific blockchain tools', 'infrastructural facility, and 'government policy and support' are mainly found in the research. According to the data, "availability of specific blockchain tools," "infrastructural facility," and "government policy and support" all influence blockchain adoption in the freight transportation sector. Shrestha A.K., Vassileva J. and Deters R. (2020) explored the "A Blockchain Platform for User Data Sharing Ensuring User Control and Incentives the appropriate platform on the criteria of performance", the paper describes a performance evaluation of the new platform for measuring and evaluating performance on the basis of analysing latency and memory consumption. For measuring the transaction cost of smart contract deployment, three test scenarios were used. The results show that the node responded quickly in all cases and at a reasonable transaction cost. Xu, M., Chen, X., \& Kou, G. (2019) explained that the concepts of bitcoin 
and blockchain were first proposed in the year 2008 by Satoshi Nakamoto. He has described the way to combing open distributed ledeger and crytology into digital currency application (Nakamoto, 2008). The evolution of blockchain has been a dynamic process. Blockchain application has been categorized into Blockchain 1.0, 2.0, and 3.0, based on their applications. Macdonald, M., Liu Thorrold and Julien, R (2017) compared the platform between use of bitcoin and best available platform available to the adoption of blockchain technology. The best platform is selected on the basis of its various features like documentation and support, development, and scalability. More than five platforms were analysed on the basis of various criteria.

A systematic mapping of research enables understanding the current research gaps. By reviewing the paper, it seems that most of the research has been conducted to find the challenges and benefits of blockchain accounting? Now the several research questions come in mind

A. What is the need to adopt blockchain technology?

B. Which factors are going to affect the adoption of blockchain technology in business?

C. Which platform of blockchain technology is better to adopt?

\section{Objectives of the Study}

The study focuses on the various factors that are affecting the decision of adoption of blockchain technology and influencing the user to adopting the technique. Secure and private, transparent and auditable, immutable, better transparency, reduce cost, transparency, real-time transaction, and flexible are the most influencing factors derived by applying factor analysis. The study also identifies the best suitable platform for adopting blockchain technology.

- To investigate various decisions making factors, affecting in adopting blockchain technology in the field of accounting.

- To examine existing available Block chain Technology based accounting platforms

\section{Hypotheses}

$\mathbf{H}_{\mathbf{o}}$ : All factors are equally important in order to selection of block chain technology based platform for accounting

$\mathbf{H}_{\mathbf{o} 2}$ : There is no significant difference in the available block chain technology platform from accounting point of view

\section{Material and Methods}

After intensive ROL, it is found that the following factors are responsible to select an appropriate BT based accounting platform for any business organisation:

The factors like reduced frauds errors, real-time transactions, enhanced security integrity, true traceability, better transparency, reduces cost, distributed, sustainable, secure and private, flexible, transparent and auditable, consensus-based and transactional, immutable, no intermediately has been taken for further study. On the basis of the above factors, questionnaires were prepared and sent to blockchain users who are adopting various accounting-based blockchain platforms. The factor analysis technique is used to measure the factors influencing the decision of adopting blockchain technology. On the basis of selected factor, it is tried to suggest the best Blockchain Technology based accounting platform out of the selected platform.

\subsection{Statistical tools and techniques}

Following statistical tools has been used to prove the hypothesis: 
Table 1: Statistical Tools

\begin{tabular}{|l|l|}
\hline Statistical tools & Purpose \\
\hline Factor Analysis & In order to reduce factors affecting adoption of Blockchain Technology \\
\hline 't'-test & In order to test the hypotheses \\
\hline
\end{tabular}

SPSS 21 statistical software has been administered in order to compliance statistical tools and techniques mentioned in table 1.

$\mathbf{H}_{\mathbf{o} \mathbf{1}}$ : All factors are equally important in order to selection of block chain technology based platform for accounting

The Factor analysis is applied to prove this hypothesis. KMO test is applied to measure the sampling adequacy of data used for factor analysis. It is .746 means more than o.6. It shows data used for sampling are sufficient and adequate. For the reduction of number of factors, factor analysis is applied. Its result is presented in a concise manner presenting finalised four factor including total seven components.

Table 2: Disclosure of derived four factors

\begin{tabular}{|l|c|l|c|l|l|l|l|}
\hline F1 & \multicolumn{2}{|l|}{ F2 } & F3 & F4 & loading & Variable 4 & loading \\
\hline Variable 1 & loading & Variable 2 & loading & Variable 3 & o.831 & $\begin{array}{l}\text { V8- } \\
\text { Flexible }\end{array}$ & o.899 \\
\hline V1- Secure and private & 0.816 & $\begin{array}{l}\text { V4- Better } \\
\text { Transparency }\end{array}$ & 0.79 & $\begin{array}{l}\text { V7- Real Time } \\
\text { Transaction }\end{array}$ & & & \\
\hline $\begin{array}{l}\text { V2- Transparent and } \\
\text { auditable }\end{array}$ & 0.803 & V5- Reduce Cost & 0.716 & & & & \\
\hline V3- Immutable & 0.75 & V6- Transparency & 0.786 & & & & \\
\hline
\end{tabular}

\subsection{Source- own prepared on the basis of SPSS result}

As per the result of factor analysis finally, eight variables were found that are- Secure and private, Transparent and auditable, Immutable, Better Transparency, Reduce Cost, Transparency, Real-Time Transaction and Flexible

These variables are segregated into four factors which are named secure, reliable, sustain, and flexible on the basis of their characteristics

Table 3: Naming of the factors

\begin{tabular}{|l|l|}
\hline Factor No. & Name of the factor \\
\hline F1 & Secure \\
\hline$F_{2}$ & Reliable \\
\hline F $_{3}$ & Sustain \\
\hline F4 & Flexible \\
\hline
\end{tabular}

After finding the appropriate factors further study was made to examine various Blockchain Platforms applied for accounting purposes. To meet with the next objective of the paper of examining various available platforms to adopt blockchain technology-based accounting and for identifying the factors which are influencing the selection of appropriate blockchain platform for accounting. A questionnaire was framed. A limited number of responses was received due to a little bit of adoption of blockchain technology. Further study is done with 17 responses from companies who are adopting blockchain services. This is the list of various Blockchain Platform is used by respondents 
Table 4: Adoption of various Blockchain Platform

\begin{tabular}{|l|c|}
\hline Blockchain Platform & Developers \% \\
\hline SAP HANA Blockchain & 5.882353 \\
\hline Ethereum & 35.29412 \\
\hline Hyper ledger Fabric & 11.76471 \\
\hline Obyte.org & 5.882353 \\
\hline Stellar & 5.882353 \\
\hline Learning EVM, Solidity & 5.882353 \\
\hline Quorum & 5.882353 \\
\hline In process & 23.52941 \\
\hline Total & 100 \\
\hline
\end{tabular}

This table present various available platform like hyperledger, Ethereum, EVM, Obyte, Sap Hana, Quorum and other platforms and respective players adopting the technology.

$\mathbf{H}_{\mathbf{0} 2}$ : There is no significant difference in the available blockchain technology platform from accounting point of view

Table 5: Block chain Platform on the basis of players

\begin{tabular}{|l|c|c|c|c|c|c|c|}
\hline (Likert scale based average score) & \multicolumn{7}{|c|}{} \\
\hline Column1 & Hyperledger & Ethereum & EVM & obyte & SapHana & Quorum & Other \\
\hline Players & 2 & 5 & 1 & 1 & 1 & 1 & 6 \\
\hline V1- Secure and private & 3 & 3.2 & 0 & 8 & 1 & 0 & 1.8 \\
\hline V2- Transparent and auditable & 4.5 & 4 & 0 & 6 & 0 & 0 & 2.2 \\
\hline V3- Immutable & 4.5 & 5 & 0 & 2 & 0 & 0 & 2 \\
\hline V4- Better Transparency & 4.5 & 5.2 & 0 & 5 & 0 & 0 & 2.2 \\
\hline V5- Reduce Cost & 5.5 & 0.6 & 0 & 1 & 5 & 0 & 3.2 \\
\hline V6- Transparency & 7 & 3.8 & 0 & 4 & 2 & 0 & 3 \\
\hline V7- Real Time Transaction & 2 & 6.2 & 0 & 7 & 2 & 0 & 3.4 \\
\hline V8-Flexible & 1 & 2.4 & 8 & 3 & 1 & 0 & 3.8 \\
\hline Performance & 1 & 2 & 4 & 3 & 2 & 4 & 2.8 \\
\hline Average of factors & 4 & 3.8 & 1 & 4.5 & 1.38 & 0 & 2.7 \\
\hline
\end{tabular}

This table presents various available platforms like hyperledger, Ethereum, EVM, Obyte, Sap Hana, Quorum and other platforms and respective players adopting the technology.

\begin{tabular}{|l|l|c|c|c|c|c|c|}
\hline \multirow{4}{*}{ t-test } & \multirow{2}{*}{$\mathrm{T}$} & \multirow{2}{*}{$\mathrm{Df}$} & \multirow{2}{*}{$\begin{array}{c}\text { Sig. } \\
\text { (2-tailed) }\end{array}$} & \multicolumn{2}{c|}{$\begin{array}{c}\text { Mean } \\
\text { Diff. }\end{array}$} & \multicolumn{2}{|c|}{$95 \%$ Conf. Level } \\
\cline { 7 - 9 } & & & & & Lower & Upper \\
\cline { 2 - 6 } & Platform & 2.99 & 6 & 0.024 & 2.42857 & 0.4409 & 4.4162 \\
\cline { 2 - 6 } & Performance & 6.421 & 6 & 0.001 & 2.68571 & 1.6622 & 3.7092 \\
\hline
\end{tabular}

Ho2: There is no significant difference in the available blockchain technology platform from an accounting point of view.

It presents the numbers of players adopting this technology and its performance as well as facilitating factors. Likert scale based Average score of the factors is taken and t-test technique is applied for testing the hypotheses.

The research hypothesis that all the variables are equally important is rejected as significance is less than 0.05. It means there is a significant difference among different available platform and their performance from an accounting point of view. It means one or more platforms are different. It shows performances of various platforms are not found equal. Now the question arises if all the platforms are not equal then which of these platforms is more suitable to adopt for accounting 
purposes. For this purpose, descriptive analysis has been applied.

Table 6: Comparative Analysis of selected Blockchain based accounting platform

\begin{tabular}{|l|c|c|c|c|c|c|}
\hline & $\mathrm{N}$ & Minimum & Maximum & Mean & Std. Deviation & Variance \\
\hline Hyperledger & 11 & 1.00 & 7.00 & 3.5455 & 1.91644 & 3.673 \\
\hline Ethereum & 11 & .60 & 6.20 & 3.7455 & 1.62503 & 2.641 \\
\hline EVM & 11 & .00 & 8.00 & 1.2727 & 2.53341 & 6.418 \\
\hline obyte & 11 & 1.00 & 8.00 & 4.0455 & 2.32868 & 5.423 \\
\hline SapHana & 11 & .00 & 5.00 & 1.3982 & 1.42830 & 2.040 \\
\hline Quorum & 11 & .00 & 4.00 & .4545 & 1.21356 & 1.473 \\
\hline Other & 11 & 1.80 & 6.00 & 3.0091 & 1.17000 & 1.369 \\
\hline Valid N (listwise) & 11 & & & & & \\
\hline
\end{tabular}

The table shows the descriptive statistics like mean, standard deviation, and variance. On the basis of variance, it can be said that Quorum, Sap Hana, and Ethereum platforms have less variance which shows these are more consistent. It can be said above-mentioned platforms are better in comparison to others (Obyte, EVM, and Hyperledger).

\section{Conclusion}

Blockchain technology is a ledger system, it allows for transaction documentation and settlement to happen immediately as the transaction, and auditors could get information in real and in a uniform, recurring manner. It is in demanding, preferably accepted and adopted by the corporate world. It has the capability to resolve most of the problems that are faced by corporate. A true and fair presentation of financial reporting with the high level of transparency would be possible. However, the various platforms for adopting blockchain technology discussed here like Ethereum, Quorum and hyper ledger, etc. The performance of the blockchain technology measured on the basis of responses of respondents. Finally, the platforms that are more consistent were found better in comparison to others.

Blockchain is a unique accounting system for recording transactions that includes benefits such as increased stock market transaction efficiency and lower financial service costs; automatic transaction recording eliminates data manipulation and improves transaction security. It is considered the journey in not limiting up to Triple accounting but it is a never-ending topic for research. The result showed that secure and private, transparent and auditable, immutable, better transparency, reduce cost, transparency, real-time transaction, and flexible are most likely influencing factors in adoption of blockchain technology. It is concluded that the Quorum, Sap Hana, and Ethereum, platforms are most consistent and trusted platforms for block chain technology and the blockchain platforms are found most suitable, secured and stronger platform.

\section{Acknowledgement}

The publication of this article was supported by the Rashtriya Uchchattar Shiksha Abhiyan (RUSA 2.o) sponsored project. Our sincere thanks to Ministry of Education, Government of India for funding this research grant.

\section{References}

Aslam, J., Saleem, A., Khan, N. T., \& Kim, Y. B. (2021). Factors influencing blockchain adoption in supply chain management practices: A study based on the oil industry. Journal of Innovation \& Knowledge, 6(2), $124-134$.

Blockchain technology and its potential impact on the audit and assurance profession [White paper]. CPA Canada, AICPA \& UW CISA, 1-28. 
Faccia, A., \&Petratos, P. (2021). Blockchain, Enterprise Resource Planning (ERP) and Accounting Information Systems (AIS): Research on e-Procurement and System Integration. Applied Sciences, 11(15), 6792.

Farshidi, S., Jansen, S., España, S., \&Verkleij, J. (2020). Decision support for blockchain platform selection: Three industry case studies. IEEE Transactions on Engineering Management, 67(4), 1109-1128.

Fuller, S. H., \&Markelevich, A. (2020). Should accountants care about blockchain?. Journal of Corporate Accounting \& Finance, 31(2), 34-46.

George, K., \&Patatoukas, P. N. (2021). The Blockchain Evolution and Revolution of Accounting. In Information for Efficient Decision Making: Big Data, Blockchain and Relevance (pp. 157-172).

Ibañez, J. I., Bayer, C. N., Tasca, P., \& Xu, J. (2021). The Effeciency of Single Truth: Triple-Entry Accounting. SSRN Electronic journal, 84 .

Ibanez, J. I., Bayer, C. N., Tasca, P., \& Xu, J. (2021). Triple-entry accounting, blockchain and next of kin: Towards a standardization of ledger terminology. SSRN Electronic Journal, 35.

Marrone, M., \& Hazelton, J. (2019). The disruptive and transformative potential of new technologies for accounting, accountants and accountability: A review of current literature and call for further research. Meditari Accountancy Research.

Nocerino, S. A review on the potential impact of blockchain to the accounting profession.

Orji, I. J., Kusi-Sarpong, S., Huang, S., \& Vazquez-Brust, D. (2020). Evaluating the factors that influence blockchain adoption in the freight logistics industry. Transportation Research Part E: Logistics and Transportation Review, 141, 102025.

Pedreño, E. P., Gelashvili, V., \&Nebreda, L. P. (2021). Blockchain and its application to accounting. Intangible Capital, 17(1), 1-16.

Pugna, I. B., \&Duţescu, A. (2020). Blockchain-the accounting perspective.In Proceedings of the International Conference on Business Excellence (Vol. 14, No. 1, pp. 214-224).

Reepu. (2019). Blockchain: social innovation in finance and accounting. International Journal of Management (IJM), 5 .

Shrestha AK, Vassileva J and Deters R (2020) A Blockchain Platform for User Data Sharing Ensuring User Control and Incentives. Front. Blockchain 3:497985. doi: 10.3389/fbloc.2020.497985

Stancheva-Todorova, E. P. (2020). Blockchain Applications in The Accounting Domain. Journal of International Scientific Publications, 19.

Supriadi, I., Prasetyo, H. D., \& Suprihandari, M. D. (2020). The Effect of Applying Blockchain to The Accounting and Auditing. Ilomata International Journal of Tax \& Accounting, 10.

Yli-Huumo, J., Ko, D., Choi, S., Park, S., \&Smolander, K. (2016). Where is current research on blockchain technology?-a systematic review. PloS one, 11(10), e0163477. 